\title{
A long-term risk management tool for electricity markets using swarm intelligence
}

\author{
F. Azevedo, Z.A. Vale, P.B. Moura Oliveira, H.M. Khodr
}

A B S T R A C T

This paper addresses the optimal involvement in derivatives electricity markets of a power producer to hedge against the pool price volatility. To achieve this aim, a swarm intelligence meta-heuristic optimization technique for long-term risk management tool is proposed. This tool investigates the long-term opportunities for risk hedging available for electric power producers through the use of contracts with physical (spot and forward contracts) and financial (options contracts) settlement. The producer risk preference is formulated as a utility function $(U)$ expressing the trade-off between the expectation and the variance of the return. Variance of return and the expectation are based on a forecasted scenario interval determined by a long-term price range forecasting model. This model also makes use of particle swarm optimization (PSO) to find the best parameters allow to achieve better forecasting results. On the other hand, the price estimation depends on load forecasting. This work also presents a regressive long-term load forecast model that make use of PSO to find the best parameters as well as in price estimation. The PSO technique performance has been evaluated by comparison with a Genetic Algorithm (GA) based approach. A case study is presented and the results are discussed taking into account the real price and load historical data from mainland Spanish electricity market demonstrating the effectiveness of the methodology handling this type of problems. Finally, conclusions are dully drawn.

\section{Keywords:}

Electricity markets

Load forecast

Optimization

Particle swarm optimization

Portfolio

Price forecast

Risk management

\section{Introduction}

Long-term contractual decisions are the basis of an efficient risk management. On a vertical integrated electricity market, price variations were often minimal and heavily controlled by regulators. In this structure, electricity price evolution is directly dependent on the government's social and industrial policy. The price forecasting was mainly focused on the underlying costs (namely, fuel prices and technological innovation among others). Any price forecasting made on this basis was tended to be over the long-term. With electricity markets re-regulation process, aforementioned features have been changed dramatically. Thus, ownership on this activity sector becomes private rather than public or a mixture of both. Moreover, pools or power exchanges have been introduced for wholesale trading.

Price forecast on re-regulated electricity markets is a hard task due to the high pool price volatility. Charge characteristics (seasonality, mean-reversion and load stochastic growth) and producer's characteristics (technology, generation availability, fuel prices, technical restrictions, import/export, etc.) are at the origin of high price volatility in electricity markets. Several techniques have been used for short-term price forecast in electricity markets. In [1], artificial intelligent tools were proposed to forecast spot prices, namely, a combination of neural networks and fuzzy logic. Indeed, neural networks have now an extensive use in load and in price forecast [2-6]. Fuzzy techniques mixed with neural networks are used to predict possible prices range $[7,8]$. Stochastic processes are also used to analyze time series as ARIMA processes [9]; a class of stochastic processes was used to predict next-day electricity prices in mainland Spanish and in California markets. In [10], two forecasting tools based on dynamic regression and transfer function models are presented.

However, for the market agents who want to maximize their profits and simultaneously to practice the hedge against the market price volatility, the use of forward, futures and options contracts become a constant in developed electricity markets. Those types of contracts have a maturity that goes from 1 year to several years in the future, turning more difficult the decision process related to contracts establishment if they are not supported with a robust price forecast methodology.

Due to long delivery periods of the contracts described above that make more sense to forecast the market price mean value 
for each month. Moreover, contractual positions should be continuously review (say once a month) or each time the agent needs to consider the ones already locked. After review references, we assure that this problem has not been treated deeply in the scientific literature. It is not a good practice in risk management to take contractual decisions based exclusively on a single forecasted value. In Section 3 is presented a different approach for long-term price forecast. The proposed methodology, based on regression model, aims to find a maximum and a minimum monthly Market Clearing Price (MCP) average for a programming period, with a desired confidence level $\alpha$. This method makes use of statistical information extracted from mainland Spanish market historical data. Due to the complexity of the problem, the parameters are obtained using the meta-heuristic PSO [11-14]. This model could also be applied to forecast electricity market price for more than 1 year.

The long-term price forecast makes use of the monthly load average forecast for the same period. For this reason, the authors have also developed a long-term monthly load forecast using PSO.

For both models, long-term price and load forecast, PSO performance has been evaluated by comparing it with a GA.

To find best portfolio for a market agent and particularly for producers, which allow to hedge against market price volatility and simultaneously increasing their profits. Ref. [15] proposes solutions for electricity producers in the financial risk management field for electric energy contract evaluation using efficient frontier as a tool to identify the preferred contract portfolio. In [16] a decision-support system based on stochastic simulation, optimization and multi-criteria analysis, is applied to electricity retailer. A statistical study of direct and cross hedging strategies using futures contracts in an electricity market is presented in $[17,18]$. A framework to obtain the optimal bidding strategy of a thermal price-taker producer on a pool-based electric energy market is presented in [19]. The optimal involvement in a futures electricity market of a power producer to hedge against the risk of pool price volatility using conditional Value-at-Risk as risk measure is presented in [20]. A risk-constrained stochastic programming framework to decide which forward contracts the retailer should sign and at price it must sell electricity and its expected profit is maximized at a given risk level has been proposed in [21]. A technique based on stochastic programming to optimally solve the electricity procurement problem faced by large consumer is presented in [22]. Ref. [23] analyzes the impact of the degree of unavailability of the generating unit on its forward contracting decisions.

In this work, long-term risk management tool makes use of a long-term price range forecast has been developed and discussed. The proposed long-term risk management tool aims to find the best portfolio in function of the risk aversion factor $(\lambda)$ of the producer, which maximizes the expected return and, simultaneously, allows hedging against market price volatility. To achieve this, the decision-support system maximizes a mean-variance utility function $(U)$ of the total return $(\pi)$.

In this methodology, a portfolio model based on utility functions instead of option pricing models $[24,25]$ has been used, because the financial markets on electricity markets are incomplete (hedging instruments unavailable). Uncertainties associated to generators availability, fuel prices, technical restrictions and weather conditions, turn difficult, if not impossible, to find a replicating portfolio, which perfectly matches the future spot market payoffs. The power market exercise by some agents is also a source of uncertainty. Moreover, several markets around the world are still on their recent stage, with a small number of financial tools for an efficient risk management. Another issue in power markets is that electricity cannot be stored for later use. Consequently, the strategy of buying the asset today to offset part of future losses does not apply. The closest strategy is to buy a forward or futures contracts. Therefore, the delivery price of these mentioned contracts should be equal to the expected spot market price for the delivery period, which not always happens. Consequently, the electricity markets are not "complete" (i.e., any desired financial hedges are not available at a price), so risk attitudes and mean-variance frontiers are still relevant.

PSO and GA algorithm performance are evaluated to show PSO is a very successful meta-heuristic technique for solving this problem in particular.

The paper is organized as follows: Section 2 presents a long-term load forecasting model, followed by a case study applying aforementioned model. Section 3 presents a long-term price forecasting method, followed by the application of this method to a case study. Section 4 shows the problem formulation of the risk management. Finally, Section 5 draws the relevant conclusions.

\section{Long-term load forecast}

The proposed method is based on regression models. The main goal of this methodology is to find the regression parameters that minimize the absolute error to considered load historical data for monthly time interval for 1-year period.

Load pattern is not complex as the revealed by the market price. To find the best regression parameters, load historical data of the previous 2 years has been used.

\subsection{General description}

The optimization problem that allows to find the best regression parameters for the monthly load average is given by (1) and (2):

$\operatorname{Min} \sum_{i=1}^{12}\left|C_{i, j}-\hat{C}_{i, j}\right|$

Subjected to

$\hat{C}_{i, j} \geq 0$

with

$\hat{C}_{i, j}=\omega_{1, i} \cdot C_{i-1, j}+\omega_{2, i} \cdot C_{i, j-1}+\omega_{3, i} \cdot C_{i, j-2}$

\subsection{Penalty function}

To solve the optimization problem, PSO has been used to find the best solution.

To satisfy constraint (2) for each period $i$, the penalization function (3) has been added to the optimization problem:

$p_{f}= \begin{cases}0 & \text { if } \hat{C}_{i, j} \geq 0 \\ e^{100 \times a^{2}}-1 & \text { otherwise }\end{cases}$

where

$a=\left|\hat{C}_{i, j}\right|$

\subsection{PSO and GA parameters}

Tables 1 and 2 present the parameters of PSO and GA algorithm, respectively. Besides the optimum parameters of PSO method, being also dependent on the fitness function. Experimentations show that the number of evaluations used cannot compromise the results and allow to achieve the best solution.

\subsection{Case study}

This test case uses a real load historical data (2001-2006) that has been extracted from the mainland Spanish market has been used to forecast the monthly load average for the year 2007. Fig. 1 
Table 1

PSO parameters.

\begin{tabular}{|c|c|c|c|c|c|c|c|}
\hline Number of particles & Number of iterations & Number of evaluations & $\begin{array}{l}\text { Cognitive } \\
\text { acceleration }\end{array}$ & $\begin{array}{l}\text { Social } \\
\text { acceleration }\end{array}$ & $\begin{array}{l}\text { Initial inertia } \\
\text { weight }\end{array}$ & $\begin{array}{l}\text { Final inertia } \\
\text { weight }\end{array}$ & $\begin{array}{l}\text { Maximum } \\
\text { velocity }\left(V_{\max }\right)\end{array}$ \\
\hline 20 & 20,000 & 400,000 & 2 & 2 & 0.9 & 0.2 & 0.1 \\
\hline
\end{tabular}

Table 2

GA parameters.

\begin{tabular}{|c|c|c|c|c|}
\hline Population size & Number of generations & Number of evaluations & Crossover rate & Mutation rate \\
\hline 50 & 8000 & 400,000 & 0.8 & 0.2 \\
\hline
\end{tabular}

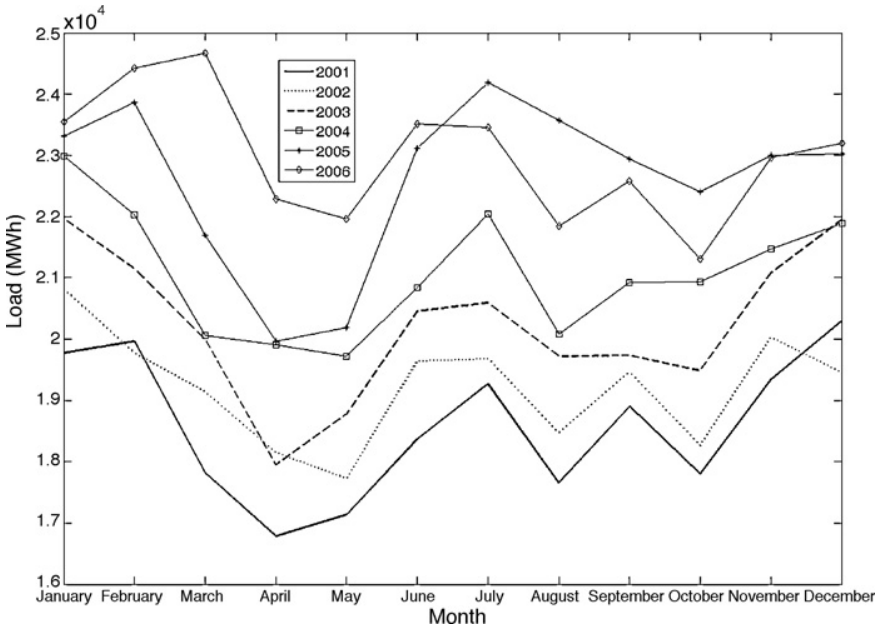

Fig. 1. Monthly load average for mainland Spanish market from 2001 to 2006.

shows the mentioned monthly load average historical evolution curve.

To find the best parameters, it was used the meta-heuristic PSO has been used and compared with a GA from performance point of view.

The stopping criterion is the maximum number of evaluations, fixed in 400,000 evaluations for both algorithms. To achieve the convergence PSO are necessary 20 particles and 20,000 iterations for PSO and a population size of 50 individuals and 8000 generations for GA. Results are presented in Tables 3-5, respectively.

It can be seen from Table 5 that, for this particular problem, PSO is faster than GA (less time) and finds better solutions (lower fitness value). These simulations have obtained by a computer Pentium 4 , 3.2 $\mathrm{GHz}$ processor and $1 \mathrm{~GB}$ of RAM.

The monthly load average forecast for the year 2007 is presented in Fig. 2.

Table 3

SO results.

\begin{tabular}{llll}
\hline & $\omega_{1, i}$ & $\omega_{2, i}$ & $\omega_{3, i}$ \\
\hline January & 0.4099 & 0.5828 & 0.0414 \\
February & 0.2155 & 0.5589 & 0.3085 \\
March & 0.5184 & 0.0417 & 0.4245 \\
April & 0.1375 & 0.3334 & 0.5762 \\
May & 0.2997 & 0.6321 & 0.0924 \\
June & 0.4830 & 0.0038 & 0.6494 \\
July & 0.1764 & 0.3302 & 0.6237 \\
August & 0.0830 & 0.8266 & 0.2521 \\
September & 0.0812 & 0.1572 & 0.8987 \\
October & 0.5528 & 0.4613 & 0.0035 \\
November & 0.2369 & 0.6747 & 0.1523 \\
December & 0.4859 & 0.3283 & 0.2155 \\
\hline
\end{tabular}

Table 4

GA results.

\begin{tabular}{llll}
\hline & $\omega_{1, i}$ & $\omega_{2, i}$ & $\omega_{3, i}$ \\
\hline January & 0.9990 & 0.0001 & 0.0625 \\
February & 0.0623 & 1.0000 & 0.0179 \\
March & 0.0010 & 0.0044 & 1.0793 \\
April & 0.0011 & 0.6140 & 0.4299 \\
May & 0.0977 & 0.5102 & 0.4351 \\
June & 0.2549 & 0.0001 & 0.8783 \\
July & 0.0007 & 0.4268 & 0.7173 \\
August & 0.6182 & 0.0620 & 0.3740 \\
September & 0.0930 & 0.8799 & 0.1183 \\
October & 0.5190 & 0.0000 & 0.5390 \\
November & 0.2506 & 0.0100 & 0.8149 \\
December & 0.0301 & 0.0156 & 0.9999
\end{tabular}

Table 5

PSO and GA fitness function comparison.

\begin{tabular}{llr}
\hline Algorithm & Fitness function value & Time (s) \\
\hline PSO & 0 & 51.45 \\
GA & 0.0148 & 662.73 \\
\hline
\end{tabular}

\section{Long-term price range forecast}

The proposed model aims to forecast the maximum and minimum monthly market price average with a desired confidence level $\alpha$, by using load and price statistical historical information data. The following methodology is deployed:

(1) For each month of the historical data, the monthly average load is divided on fixed and equal windows of size $L$. Then, for each window $L$ and for the desired confidence level $\alpha$, statistical information is extracted from the correspondent monthly average market price namely, the significance interval corre-

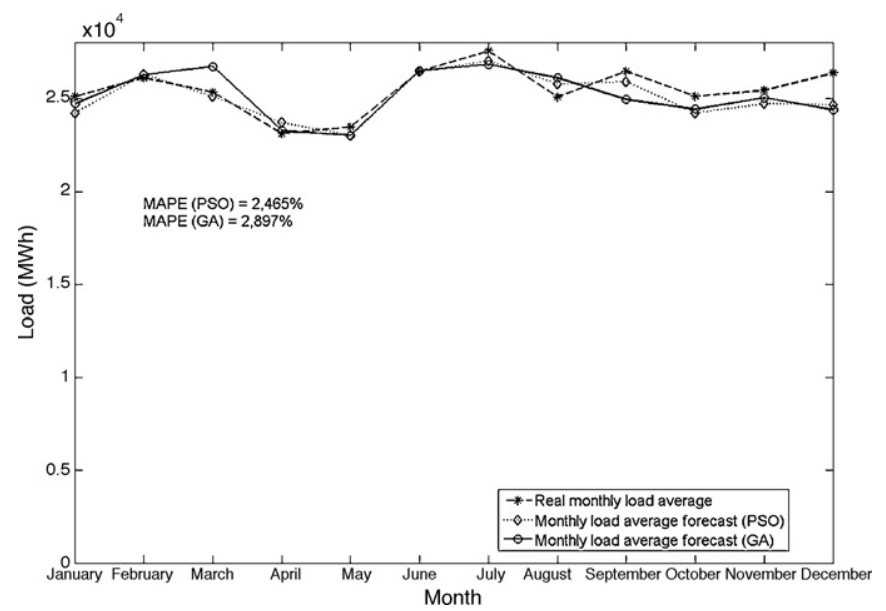

Fig. 2. Monthly load average forecast for the year 2007 on mainland Spanish market. 
sponding to maximum and minimum price is between the interval $(50+\alpha / 2)$ and $(50-\alpha / 2)$, respectively.

(2) For each historical monthly market price average, we find the correspondent maximum and minimum monthly market price average from the window $L$ that it belongs. Based on this information, for each month of the year a regression is determined for the maximum and minimum monthly market price average with the objective to minimize the absolute error considering annual historical data. The regression independent variables used are: the monthly market price average of the previous month and the monthly load average.

\subsection{Case study}

The optimization problem allow to find the best regression parameters for the maximum monthly market price average with confidence level $\alpha$, is given by (5) and (6):

$\operatorname{Min} \sum_{i=1}^{12} \sum_{j=1}^{N}\left|P_{i, j}^{\max , \alpha}-\hat{P}_{i, j}^{\max , \alpha}\right|$

Subjected to :

$\hat{P}_{i, j}^{\max , \alpha} \geq 0$

with

$\hat{P}_{i, j}^{\max , \alpha}=\alpha_{1, i} \cdot C_{i, j}+\alpha_{2, i} \cdot P_{i-1, j}$

The optimization problem allow to find the best regression parameters for the minimum monthly market price average with confidence level $\alpha$, is formulated by (7) and (8):

$\operatorname{Min} \sum_{i=1}^{12} \sum_{j=1}^{N}\left|P_{i, j}^{\min , \alpha}-\hat{P}_{i, j}^{m i n, \alpha}\right|$

Subjected to :

$\hat{P}_{i, j}^{\min , \alpha} \geq 0$

with

$\hat{P}_{i, j}^{\min , \alpha}=\beta_{1, i} \cdot C_{i, j}+\beta_{2, i} \cdot P_{i-1, j}$

After finding the best regression parameters for the maximum and minimum monthly market price average, it is necessary to forecast the load for the months which is intended to forecast the monthly market price average range.

To forecast monthly market price average range for the month $i,(6)$ and (8) should be changed to (9) and (10), respectively:

$\hat{P}_{i, j}^{\max , \alpha}=\alpha_{1, i} \cdot \hat{C}_{i}+\alpha_{2, i} \cdot P_{i-1}$

$\hat{P}_{i, j}^{\min , \alpha}=\beta_{1, i} \cdot \hat{C}_{i}+\beta_{2, i} \cdot P_{i-1}$

Due to the high value of the monthly load average, the monthly market price average, a scale factor $\delta$ is applied to the monthly load average to avoid high values of $\alpha_{1, i}$ and $\beta_{1, i}$ to facilitate the convergence of the optimization problems.
Based on the aforementioned idea, Eqs. (9) and (10) should be changed to (11) and (12) as follows:

$\hat{P}_{i, j}^{\max }=\alpha_{1, i} \cdot \hat{C}_{i} \cdot \delta+\alpha_{2, i} \cdot P_{i-1}$

$\hat{P}_{i, j}^{\min }=\beta_{1, i} \cdot \hat{C}_{i} \cdot \delta+\beta_{2, i} \cdot P_{i-1}$

This method can also be used to forecast the monthly market price average range for several programming periods ahead using the following strategy: the average of monthly market price average range forecast for the programming period $p$ will act as the previous monthly market price average for the programming period $p+1$.

To solve the optimization problems the PSO algorithm was used and its' performance compared with the performance of a GA.

\subsection{Penalty functions}

To find the best solution of problems (5) and (7) PSO and GA algorithm were used. In order to satisfy the constraint of the optimization problem (5), the penalty function given by (13) and (14) was used:

$p= \begin{cases}0 & \text { if } \hat{P}_{i, j}^{\max , \alpha} \geq 0 \\ e^{100 \times b^{2}}-1 & \text { otherwise }\end{cases}$

with

$b=\left|\hat{P}_{i, j}^{\max , \alpha}\right|$

To satisfy the constraint of the optimization problem (7) the penalty function given by (15) and (16) is used:

$p_{2}= \begin{cases}0 & \text { if } \hat{P}_{i, j}^{\min , \alpha} \geq 0 \\ e^{100 \times c^{2}}-1 & \text { otherwise }\end{cases}$

with

$c=\left|\hat{P}_{i, j}^{\min , \alpha}\right|$

\subsection{PSO and GA parameters}

The PSO and GA parameters used to find the best solution are presented in Tables 6 and 7, respectively. Besides the optimum parameters of PSO method, being also dependent on the fitness function. Experimentations show that the number of evaluations used cannot compromise the results and allow to achieve the best solution.

\subsection{Case study}

To test our model, in this section the monthly market price average is forecasted for the year 2007 in mainland Spanish market with a confidence level $\alpha=95 \%$. It is assumed that $t=0$ corresponds to 31 December of the year 2006. The historical data used was the monthly market price and load average from 2001 to 2006 presented in Figs. 1 and 3, respectively.

Table 6

PSO parameters.

\begin{tabular}{|c|c|c|c|c|c|c|c|}
\hline $\begin{array}{l}\text { Number of } \\
\text { particles }\end{array}$ & $\begin{array}{l}\text { Number of } \\
\text { iterations }\end{array}$ & $\begin{array}{l}\text { Number of } \\
\text { evaluations }\end{array}$ & $\begin{array}{l}\text { Cognitive } \\
\text { acceleration }\end{array}$ & $\begin{array}{l}\text { Social } \\
\text { acceleration }\end{array}$ & $\begin{array}{l}\text { Initial inertia } \\
\text { weight }\end{array}$ & $\begin{array}{l}\text { Final inertia } \\
\text { weight }\end{array}$ & $\begin{array}{l}\text { Maximum } \\
\text { velocity }\left(V_{\max }\right)\end{array}$ \\
\hline 20 & 20,000 & 400,000 & 2 & 2 & 0.9 & 0.2 & 0.2 \\
\hline
\end{tabular}

Table 7

GA parameters.

\begin{tabular}{|c|c|c|c|c|}
\hline Population size & Number of generations & Number of evaluations & Crossover rate & Mutation rate \\
\hline 50 & 8000 & 400,000 & 0.8 & 0.2 \\
\hline
\end{tabular}




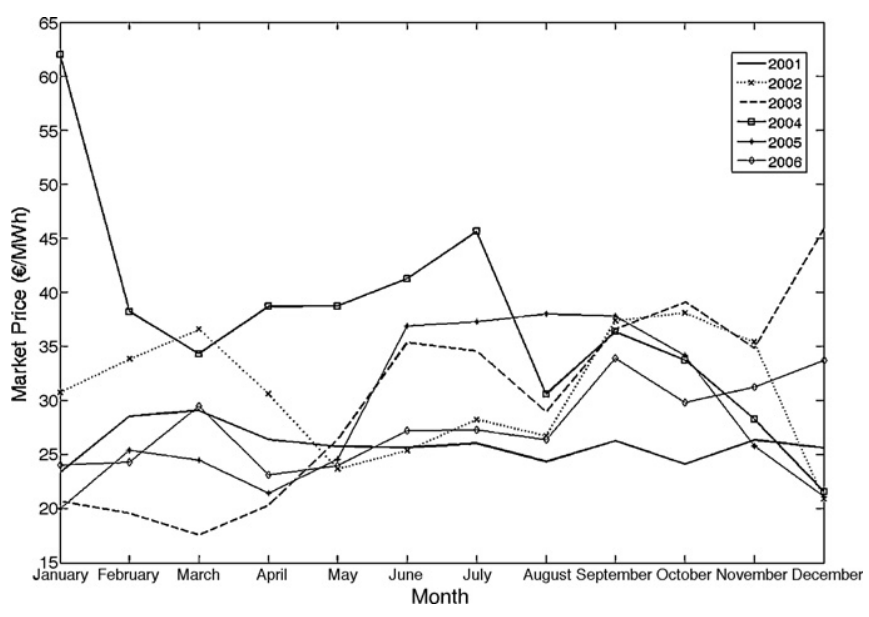

Fig. 3. Monthly market price average for mainland Spanish market from 2001 to 2006.

Table 8

Average of the regression parameters using PSO algorithm.

\begin{tabular}{lrrrr}
\hline & $\alpha_{1, i}$ & \multicolumn{1}{l}{$\alpha_{2, i}$} & $\beta_{1, i}$ & \multicolumn{1}{l}{$\beta_{2, i}$} \\
\hline January & 0.4456 & 0.0277 & 0.2546 & 0.0157 \\
February & 0.1891 & 0.6436 & 0.2953 & -0.0695 \\
March & 0.1981 & 0.7087 & 0.2843 & -0.0235 \\
April & 0.4574 & -0.0237 & 0.3104 & 0.0199 \\
May & 0.3853 & 0.2774 & 0.3096 & 0.1273 \\
June & 0.2907 & 0.5413 & 0.2126 & 0.5159 \\
July & 0.4171 & 0.1400 & 0.2787 & 0.1700 \\
August & 0.4721 & -0.1493 & 0.3216 & 0.0456 \\
September & 0.3312 & 0.4298 & 0.3263 & 0.1708 \\
October & -0.0319 & 1.3919 & 0.2886 & 0.2084 \\
November & 0.1773 & 0.6830 & 0.2266 & 0.3287 \\
December & 0.4767 & 0.0638 & 0.1978 & 0.3137 \\
\hline
\end{tabular}

The proposed model needs the monthly forecasted load for the year 2007. The results of PSO algorithm have been used and presented in Fig. 2 because it achieve better results, namely lower Mean Absolute Percentage Error (MAPE).

PSO performance is compared with the one achieved by GA. The stopping criterion is the maximum number of evaluations, fixed in 400,000 evaluations for both algorithms. To achieve the convergence PSO are necessary 20 particles and 20,000 iterations for PSO and a population size of 50 individuals and 8000 generations for GA. Due to random initialization, the trajectory for each run is different; so 10 runs are used to find the average and the standard deviation of the results. The scale factor $\delta$ applied the monthly load average was set equal to $2 \times 10^{3}$.

Results are presented in Tables 8 and 9, respectively.

The regression parameters standard deviation for the monthly market price range forecast using the PSO and a GA is presented in Tables 10 and 11 , respectively.

Table 9

Average of the regression parameters using GA.

\begin{tabular}{llllr}
\hline & $\alpha_{1, i}$ & $\alpha_{2, i}$ & $\beta_{1, i}$ & \multicolumn{1}{c}{$\beta_{2, i}$} \\
\hline January & 0.4478 & 0.0155 & 0.2832 & -0.0545 \\
February & 0.1764 & 0.7185 & 0.2635 & 0.0914 \\
March & 0.2563 & 0.5457 & 0.2726 & 0.0362 \\
April & 0.4052 & 0.2419 & 0.2430 & 0.2249 \\
May & 0.3921 & 0.2444 & 0.3188 & 0.0841 \\
June & 0.3203 & 0.4612 & 0.2955 & 0.1264 \\
July & 0.3809 & 0.2797 & 0.1399 & 0.6120 \\
August & 0.4235 & -0.0337 & 0.3216 & 0.0458 \\
September & 0.2061 & 0.9289 & 0.4496 & -0.2597 \\
October & 0.0538 & 1.1331 & 0.3700 & 0.0094 \\
November & 0.0494 & 1.0624 & 0.2076 & 0.4003 \\
December & 0.4893 & 0.0074 & 0.1555 & 0.4396 \\
\hline
\end{tabular}

Table 10

Standard deviation of the regression parameters using PSO algorithm.

\begin{tabular}{lllll}
\hline & $\alpha_{1, i}$ & $\alpha_{2, i}$ & $\beta_{1, i}$ & $\beta_{2, i}$ \\
\hline January & 0.0001 & 0.0004 & 0.0002 & 0.0005 \\
February & 0.0000 & 0.0001 & 0.0002 & 0.0005 \\
March & 0.0116 & 0.0488 & 0.0040 & 0.0202 \\
April & 0.0002 & 0.0006 & 0.0035 & 0.0143 \\
May & 0.0023 & 0.0106 & 0.0002 & 0.0007 \\
June & 0.0000 & 0.0000 & 0.0001 & 0.0003 \\
July & 0.0691 & 0.2512 & 0.0094 & 0.0250 \\
August & 0.0064 & 0.0141 & 0.0004 & 0.0008 \\
September & 0.0853 & 0.2917 & 0.0029 & 0.0112 \\
October & 0.1287 & 0.3145 & 0.0550 & 0.1721 \\
November & 0.0059 & 0.0159 & 0.0076 & 0.0282 \\
December & 0.0119 & 0.0535 & 0.0146 & 0.0656 \\
\hline
\end{tabular}

Table 11

Standard deviation of the regression parameters using GA.

\begin{tabular}{lllll}
\hline & $\alpha_{1, i}$ & $\alpha_{2, i}$ & $\beta_{1, i}$ & $\beta_{2, i}$ \\
\hline January & 0.0088 & 0.0276 & 0.0740 & 0.3483 \\
February & 0.0007 & 0.0041 & 0.0182 & 0.0920 \\
March & 0.0212 & 0.0563 & 0.0088 & 0.0311 \\
April & 0.0823 & 0.3006 & 0.0343 & 0.0910 \\
May & 0.0166 & 0.0783 & 0.0110 & 0.0515 \\
June & 0.0105 & 0.0279 & 0.0037 & 0.0157 \\
July & 0.0631 & 0.2216 & 0.0898 & 0.2774 \\
August & 0.0143 & 0.0404 & 0.0449 & 0.1063 \\
September & 0.0774 & 0.3150 & 0.0653 & 0.2385 \\
October & 0.0361 & 0.1133 & 0.1728 & 0.4750 \\
November & 0.0469 & 0.1465 & 0.0049 & 0.0165 \\
December & 0.0113 & 0.0506 & 0.0187 & 0.0519 \\
\hline
\end{tabular}

The mean and the standard deviation of the fitness functions for the 10 runs are presented in Table 12 . Table 12 also includes the mean time necessary to reach the optimal solution for PSO and GA.

Analyzing Tables 10 and 11, it can be verified that, for this particular problem, PSO solutions are more robust (smaller standard deviation values) than the ones attained with the GA.

It can be verified from Table 12 that, for this particular problem, PSO is faster than GA (smaller mean time), finds better solutions (smaller mean fitness value) and is more robust (smaller standard deviation values). These simulations were on the same computer.

The monthly market price range forecast for the year 2007 in mainland Spanish market with confidence level $\alpha=95 \%$, using the PSO and GA are presented in Figs. 4 and 5, respectively.

In these figures we verify results PSO are better for this particular problem when compared with GA results, because the sum of the MAPE for the maximum and minimum monthly market price average forecast is lower for PSO. Also from the same figures it is possible to verify the monthly market price average range forecast include in $91.67 \%$ the real monthly market price average.

Comparing Figs. 4 and 5, we verify that for the December the monthly market price average range forecast does not include the real monthly market price average. This occur because from Fig. 3, with the exception of the year 2002, the monthly market price average variation between November and December was not so high when compared with the same period of the year 2007. Indeed, we use a regression model, with objective to minimize absolute error for the historical data. This is not possible to capture such pattern.

Table 12

PSO and GA fitness function comparison.

\begin{tabular}{lllr}
\hline Algorithm & Mean & Std. Dev. & Mean time $(\mathrm{s})$ \\
\hline PSO (max) & 16.0977 & 0.1138 & 79.2476 \\
GA (max) & 17.1949 & 0.2745 & 1939.5000 \\
PSO (min) & 7.5360 & 0.0928 & 72.5983 \\
GA (min) & 9.2295 & 0.3201 & 1005.9000 \\
\hline
\end{tabular}




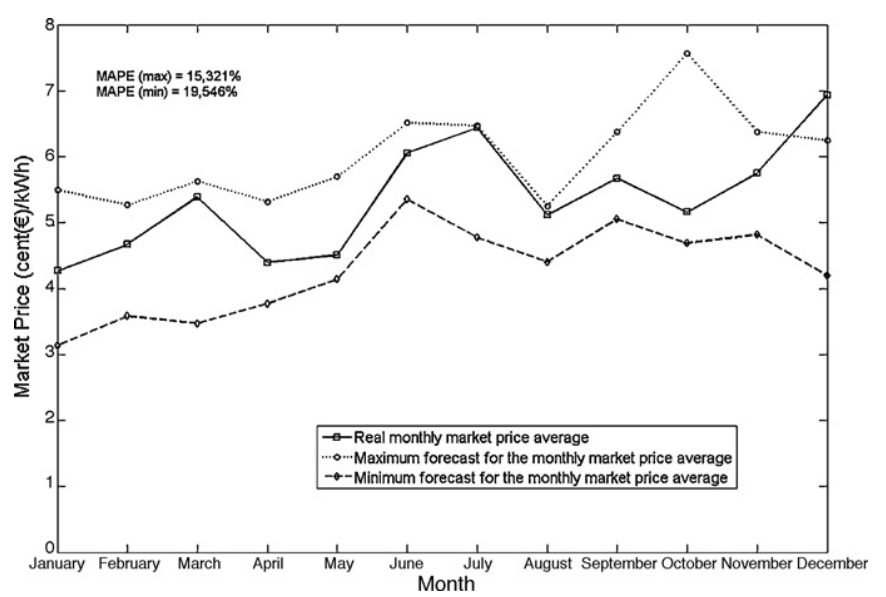

Fig. 4. Monthly market price range forecast for the year 2007 in mainland Spanish market, with confidence level $\alpha=95 \%$, using the PSO algorithm.

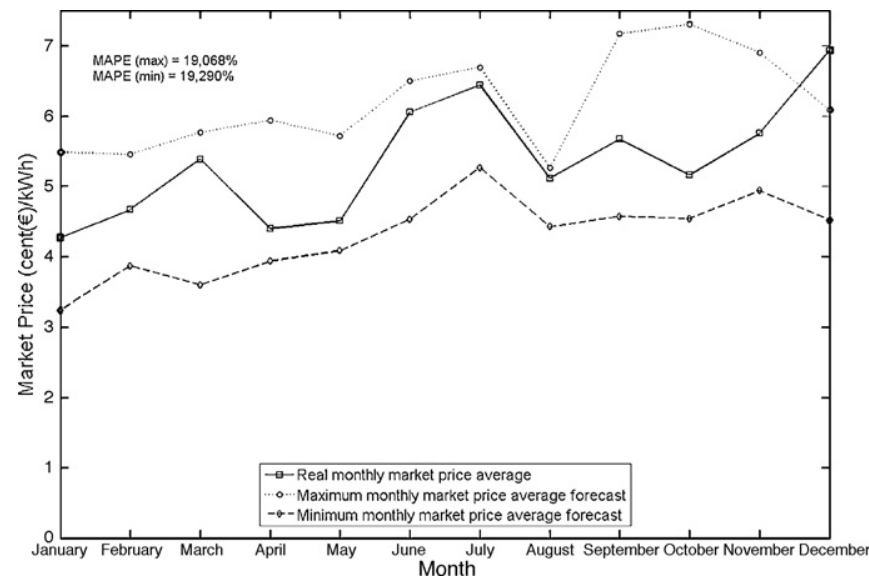

Fig. 5. Monthly market price range forecast for the year 2007 in mainland Spanish market, with confidence level $\alpha=95 \%$, using the GA.

Maybe these results will be better than the obtained results, if we have other type of information, like temperature for example.

\section{Long-term risk management}

Finding the optimal portfolio of contracts for a deregulated electricity market agent is a hard task due to the characteristics of the "product" electricity and to the non-linear characteristics of the available contracts.

This paper presents a new methodology for long-term risk management tool, taking into account, large period price forecast and contractual diversification that are the key issue for an efficient risk management. To achieve this, it is assumed that producers can make use of contracts with physical settlement (spot and forward contracts) and contracts with financial settlement (options contracts). It has been solved by a combination of PSO and regression algorithms.

\subsection{Spot contracts}

Electricity market design is mainly dependent of financial, political and ideology reasons. Therefore, deregulated electricity markets design varies from country to another. However, spot market becomes the core of the main deregulated electricity markets around the world. Producers make extensive use of this market to sell their energy on an hour or half-hour basis. The revenue from the short position (who sells has a short position and who buys has a long position) obtained by the producer is dependent of the period $i$ and scenario $j$ and is given by (17):

$r_{i, j}^{s S}=M C P_{i, j} \cdot e_{i}^{s S}$

\subsection{Forward contracts}

The strategy of buying the asset today to offset part of future losses does not apply. The closer strategy is to buy a forward or futures contracts. Forward contracts are bilateral agreements in which two parts agree mutually on the characteristics (quantity, price, point of delivery and date/time). The payment is made only on a future date, eliminating the risk associated to price variation.

The producer revenue from a short forward position on forward contracts is given by (18). In this risk management tool it was considered that the delivery period for forward contracts is the same of all period in analysis:

$r^{s f}=k^{s f} \cdot e^{s f}$

The delivery price is fixed on forward contracts. So, its revenue is only dependent on the delivery price and quantity established in the contract.

To avoid producers take advantage of any arbitrage opportunity, this long-term risk management tool does not allow long positions on forward contracts.

\subsection{Options contracts}

On options contracts the buyer have the right, but not the obligation, to exercise the contract. Based on that, there are four positions on options contracts: short call, long call, short put and long put. However, risk management tool only allows the producers to establish short call and long put positions. These positions are similar to the positions of the producer can establish to sell the produced energy with physical settlement. If producer is allowed to establish four positions types, quantities to practice the hedge would be almost infinite if a financial limit is not established.

It was assumed they are financial type and European-style options (European-style options can only be exercised at the beginning of the delivery date while American-style options can be exercised at any time until the delivery date).

The payoff for the short call position is given by (19):

$P_{i, j}^{s c}=e^{s c} \cdot\left[\min \left(k^{s c}-M C P_{i, j}, 0\right)+p^{s c}\right]$

From Eq. (19) it is clear that the buyer only exercises the call option if the Market Clearing Price is higher than the delivery price. Also we can see the seller (producer) payoff is positive only if the Market Clearing Price at the expiration date is lower than the call option exercise price plus the premium.

For the long put position, option buyer (producer) will exercise it if the MCP is lower than the exercise price.

The payoff for long put position is given by (20):

$P_{i, j}^{l p}=e^{l p} \cdot\left[\max \left(k^{l p}-M C P_{i, j}, 0\right)-p^{l p}\right]$

From Eq. (20) it can be seem the long put position payoff is positive only if the MCP is higher than the exercise price.

\subsection{Mathematical optimization problem}

To find optimal energy quantities establishing on each contract type, it was developed an optimization problem based on a meanvariance of the return. This formulation allows finding the optimal energy quantities that maximizes the profits and simultaneously practices the hedge against the MCP volatility in function of the producer risk aversion factor. 
The mathematical formulation is stated as following:

Maximize $U(\pi)=E(\pi)-\lambda \cdot \operatorname{Var}(\pi)$

Subjected to:

$e_{\min } \leq e_{i}^{c s}+e^{c f} \leq e_{\max }$

$e_{i}^{c s}, e^{c f}, e^{c c}, e^{l p} \geq 0$

where

$E(\pi)=E\left(\pi^{\max }\right)+E\left(\pi^{\min }\right)$

and

$\operatorname{Var}(\pi)=\sum_{i=1}^{2} \sum_{j=1}^{2} \operatorname{cov}_{i, j}\left(\pi^{\max }, \pi^{\min }\right)$

with

$\pi^{\max }=\left[\pi_{1}^{\max }, \ldots, \pi_{T}^{\max }\right]$

and

$\pi^{\min }=\left[\pi_{1}^{\min }, \ldots, \pi_{T}^{\min }\right]$

The mean-variance formulation resemble closely the Valueat-Risk (VaR) formulation and have as main advantage to be computationally more efficient for a given risk aversion factor $\lambda$. Moreover, VaR formulation needs higher order of information about the joint probability distribution of the payoffs and is highly sensitive to the high impact of low probability events, which create "fat tails" in payoff distribution. In this formulation we assumed the risk aversion factor $\lambda$ is equal for the whole period in analysis.

The return $\pi$ for each period $i$, expressed in Eur, is a function of the considered minimum or maximum price forecast scenario $j$ for that period, and is equal to the sum of all revenues and options payoffs minus the costs of production.

Mathematically, the return $\pi$ is

$\pi_{i, j}=r_{i, j}^{s s}+r^{s f}+P_{i, j}^{s c}+P_{i, j}^{l p}-C_{i, j}$

with

$C_{i, j}=C\left(e_{i}^{s s}+e^{s f}\right)$

Options contracts have financial settlement; the total production cost is only dependent on the energy that the producer will sell on spot market, and on forward contracts, meaning that is only dependent of the energy established on contracts with physical settlement.

\subsection{Penalty functions}

Due to optimization problem complexity, PSO was used to find the optimal solution and results were compared with GA results.

To satisfy constraint (22) for each period $i$, penalty function (30) and (31) is added to (21):

$p_{f 1}=\left\{\begin{array}{ll}0 & \text { if } e \geq e_{\min } \\ e^{100 \times d^{2}}-1 & \text { otherwise }\end{array}\right.$ and $e \leq e_{\max }$

where

$d=\min \left[\left|e-e_{\min }\right|,\left|e-e_{\max }\right|\right]$

To satisfy constraint (23) for each period $i$, penalty function (32) and (33) is added to (21):

$p_{f 2}= \begin{cases}0 & \text { if } e_{i}^{s s, s f, s c, l p} \geq 0 \\ e^{100 \times e^{2}}-1 & \text { otherwise }\end{cases}$

where

$e=\left|e_{i}^{s s, s f, s c, l p}\right|$

\subsection{PSO and GA parameters}

The parameters of PSO and GA, used finding the best solution are presented in Tables 13 and 14, respectively. Besides these parameters being dependent on the fitness function, experimentations show that the number of evaluations used does not compromise the results and allow achieving the optimal solution.

\subsection{Producer characteristics}

It was assumed that producer cost function is equal for the entire period in analysis ( 1 year) and is given by Eq. (34):

$C\left(P_{g}\right)=100+0.3 \cdot P_{g}+0.02 \cdot P_{g}^{2}$

where $P_{g}$ is in MW, $C$ in Eur $/ \mathrm{h}, P_{g}^{\max }=200 \mathrm{MW}$ and $P_{g}^{\min }=5 \mathrm{MW}$.

The cost of sales (like taxes, market commissions and others) is not addressed. Moreover, there is just as much risk in the cost of sales as there is in the generation of revenue.

\subsection{Contracts characteristics}

Options contracts characteristics with delivery period for the year 2007 are presented in Table 15.

It was assumed that forward contracts with delivery period for the year 2007 are traded at a price equal to $40 \mathrm{Eur} / \mathrm{MWh}$.

\subsection{Case study}

In this case a producer aims (in December 2006) to find the optimal contracts portfolio for the entire year of 2007. However, although to be beyond the purpose of this work, the producer must adjust its contractual positions continuously (say once a month) and whenever, he needs to reconsider his contractual positions already established in forward and other contracts, before adjusting the portfolio.

Although PSO achieve better results on monthly price range average forecast, Fig. 4 present the results for the year 2007.

An evaluation of PSO and GA performance for this particular problem has been carried out. The algorithms' stopping criterion was the maximum number of evaluations (fixed in 400,000 evaluations). With 20 particles in the PSO 20,000 iterations were performed. For GA a population size of 50 individuals and 8000 generations was used. Due to random initialization, the trajectory for each run is different; so, we used 10 runs to calculate the average and the standard deviation of the results.

Due to the problem complexity, the entire period was divided in sub-periods of one month of duration allowing to reduce the number of variables and, consequently, turning the optimization problem lighter.

In Tables 16 and 17 results are presented for the average quantities, in MWh, for each contractual position and risk aversion factor using PSO and GA, respectively.

The standard deviation of the results using PSO and GA is presented in Tables 18 and 19, respectively.

Comparing the standard deviation for each solution (Tables 18 and 19), we conclude that PSO is more robust than the GA.

The mean and the standard deviation of the fitness functions for the 10 runs and for each risk aversion factor are presented in Table 20. Table 20 also includes the mean time necessary to reach the optimal solution for PSO and GA.

It can be verified from Table 20 that, for this particular problem, PSO is faster than GA (smaller mean time), finds better solutions (smaller mean fitness value) and is more robust (smaller standard 
Table 13

PSO parameters.

\begin{tabular}{|c|c|c|c|c|c|c|c|}
\hline $\begin{array}{l}\text { Number of } \\
\text { particles }\end{array}$ & $\begin{array}{l}\text { Number of } \\
\text { iterations }\end{array}$ & $\begin{array}{l}\text { Number of } \\
\text { evaluations }\end{array}$ & $\begin{array}{l}\text { Cognitive } \\
\text { acceleration }\end{array}$ & $\begin{array}{l}\text { Social } \\
\text { acceleration }\end{array}$ & $\begin{array}{l}\text { Initial inertia } \\
\text { weight }\end{array}$ & $\begin{array}{l}\text { Final inertia } \\
\text { weight }\end{array}$ & $\begin{array}{l}\text { Maximum } \\
\text { velocity }\left(V_{\max }\right)\end{array}$ \\
\hline 20 & 20,000 & 400,000 & 2 & 2 & 0.9 & 0.4 & 10 \\
\hline
\end{tabular}

Table 14

GA parameters.

\begin{tabular}{|c|c|c|c|c|}
\hline Population size & Number of generations & Number of evaluations & Crossover rate & Mutation rate \\
\hline 50 & 8000 & 400,000 & 0.8 & 0.2 \\
\hline
\end{tabular}

deviation). These simulations were made on an ASUS L5GX laptop, P4 3.2 GHz processor and $1 \mathrm{~GB}$ of memory.

Because PSO achieve better results in this particular problem, in Figs. 6 and 7 is presented its results for the expected return and the associated risk for each month, as function of the risk aversion factor $\lambda$, respectively.

From Figs. 6 and 7 we conclude that, for the same risk aversion factor $\lambda$, the bigger the expected return the bigger the risk (standard deviation of the return) that the producer is exposed to. Analyzing Figs. 7 and 8 we verify that the risk (standard deviation of the return) is inversely proportional to the risk aversion factor $\lambda$, and so is the energy that the producer will sell in the spot market.

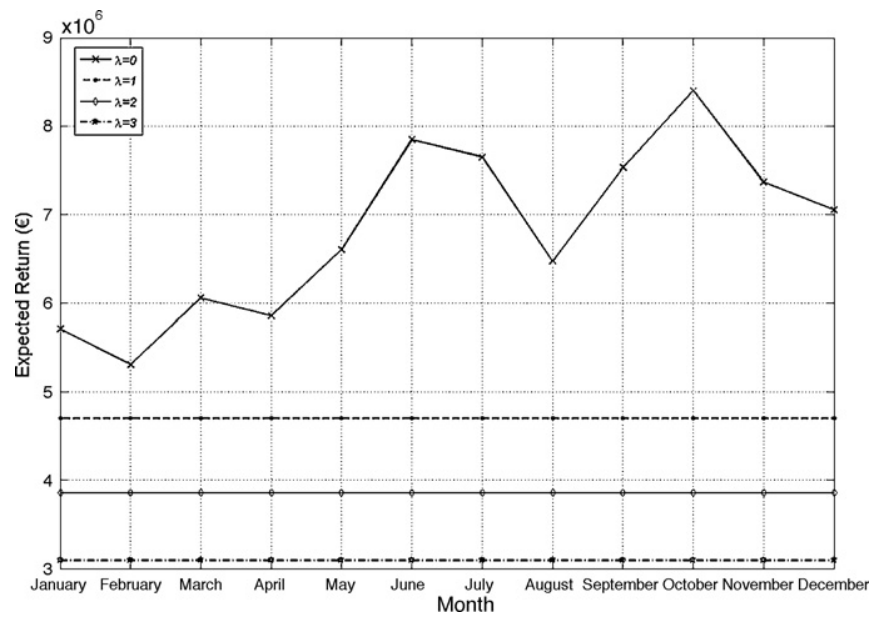

Fig. 6. Producer expected return in function of risk aversion factor $\lambda$.

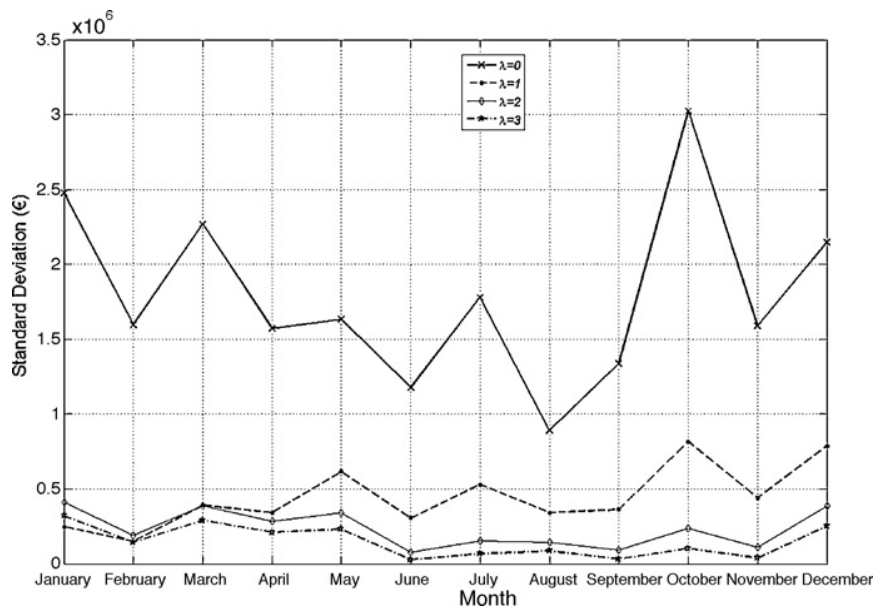

Fig. 7. Risk in function of risk aversion factor $\lambda$.

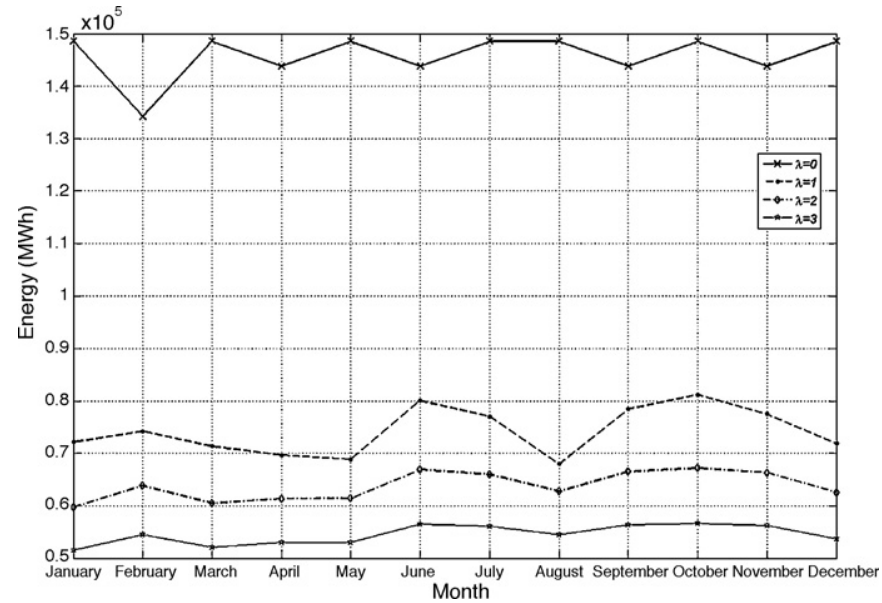

Fig. 8. Optimal energy quantities that producer should sell in spot market in function of risk aversion factor $\lambda$.

This happens because the lower the risk aversion factor the most indifferent the producer will be to the risk and therefore he will have more risky attitudes and sell more energy on the spot market as it can be seen in Fig. 8 .

Table 15

Options contracts characteristics.

\begin{tabular}{lll}
\hline & Exercise price (Eur/MWh) & Premium (Eur/MWh) \\
\hline Short call & 42.00 & 2.50 \\
Long put & 45.00 & 5.00 \\
\hline
\end{tabular}

Table 16

Average quantity, in MWh, to establish by contractual position and risk aversion factor using PSO.

\begin{tabular}{lllll}
\hline Positions & \multicolumn{4}{l}{ Average quantity (MWh) } \\
\cline { 2 - 5 } & $\lambda=0$ & $\lambda=1$ & $\lambda=2$ & $\lambda=3$ \\
\hline Short spot & $2.1 \times 10^{6}$ & $1.2 \times 10^{6}$ & $9.9 \times 10^{5}$ & $7.7 \times 10^{5}$ \\
Short forward & $2.7 \times 10^{3}$ & $6.4 \times 10^{5}$ & $5.9 \times 10^{5}$ & $3.8 \times 10^{5}$ \\
Short call & 0.839 & $1.3 \times 10^{6}$ & $1.4 \times 10^{6}$ & $5.4 \times 10^{5}$ \\
Long put & 0.250 & $6.9 \times 10^{5}$ & $1.3 \times 10^{6}$ & $7.2 \times 10^{5}$ \\
\hline
\end{tabular}

Table 17

Average quantity, in MWh, to establish by contractual position and risk aversion factor using GA.

\begin{tabular}{lllll}
\hline Positions & \multicolumn{4}{l}{ Average quantity (MWh) } \\
\cline { 2 - 5 } & $\lambda=0$ & $\lambda=1$ & $\lambda=2$ & $\lambda=3$ \\
\hline Short spot & $1.8 \times 10^{6}$ & $1.1 \times 10^{6}$ & $1.3 \times 10^{6}$ & $1.1 \times 10^{6}$ \\
Short forward & $2.4 \times 10^{5}$ & $5.4 \times 10^{5}$ & $4.4 \times 10^{5}$ & $4.8 \times 10^{5}$ \\
Short call & 145.017 & $8.7 \times 10^{5}$ & $1.4 \times 10^{6}$ & $1.0 \times 10^{7}$ \\
Long put & 444.929 & $9.8 \times 10^{5}$ & $7.8 \times 10^{5}$ & $4.1 \times 10^{5}$ \\
\hline
\end{tabular}


Table 18

Standard deviation quantity, in MWh, to establish by contractual position and risk aversion factor using PSO.

\begin{tabular}{llrrr}
\hline \multirow{2}{*}{ Positions } & \multicolumn{3}{l}{ Std. Dev. (MWh) } \\
\cline { 2 - 5 } & $\lambda=0$ & $\lambda=1$ & \multicolumn{1}{l}{$\lambda=2$} & \multicolumn{1}{l}{$\lambda=3$} \\
\hline Short spot & 0.004 & 2.026 & 112.788 & 24.277 \\
Short forward & $1.7 \times 10^{-4}$ & 1.028 & 6.233 & 0.979 \\
Short call & $6.1 \times 10^{-6}$ & 26.243 & 7.797 & 30.443 \\
Long put & $8.6 \times 10^{-6}$ & 45.682 & 75.483 & 5.041 \\
\hline
\end{tabular}

Table 19

Standard deviation quantity, in MWh, to establish by contractual position and risk aversion factor using GA

\begin{tabular}{lcrrr}
\hline Positions & \multicolumn{4}{l}{ Std. Dev. (MWh) } \\
\cline { 2 - 5 } & \multicolumn{1}{l}{$\lambda=0$} & $\lambda=1$ & \multicolumn{1}{l}{$\lambda=2$} & \multicolumn{1}{c}{$\lambda=3$} \\
\hline Short spot & 213.693 & 6.267 & 227.004 & 321.845 \\
Short forward & 17.807 & 1.534 & 2.237 & 5.292 \\
Short call & 0.0079 & 68.864 & 29.499 & 159.678 \\
Long put & 0.0229 & 145.471 & 94.215 & 9.6719 \\
\hline
\end{tabular}

Table 20

PSO and GA fitness function comparison.

\begin{tabular}{llll}
\hline Algorithm & Mean & Std. Dev. & Mean time $(\mathrm{s})$ \\
\hline PSO $(\lambda=0)$ & $1.3639 \times 10^{7}$ & 10.9801 & 113.1464 \\
GA $(\lambda=0)$ & $1.3181 \times 10^{7}$ & $2.9971 \times 10^{5}$ & 858.5784 \\
PSO $(\lambda=1)$ & $9.5269 \times 10^{6}$ & $1.8706 \times 10^{5}$ & 107.2944 \\
GA $(\lambda=1)$ & $7.8527 \times 10^{6}$ & $7.4777 \times 10^{5}$ & 885.0692 \\
PSO $(\lambda=2)$ & $7.5300 \times 10^{6}$ & $2.6324 \times 10^{5}$ & 107.4961 \\
GA $(\lambda=2)$ & $1.8101 \times 10^{6}$ & $2.3825 \times 10^{6}$ & 880.0213 \\
PSO $(\lambda=3)$ & $6.3729 \times 10^{6}$ & $2.7286 \times 10^{5}$ & 106.3816 \\
GA $(\lambda=3)$ & $4.6687 \times 10^{6}$ & $4.5523 \times 10^{5}$ & 868.8086 \\
\hline
\end{tabular}

\section{Conclusions}

In this paper an effective long-term risk management tool has been proposed that allows producers to maximize their expected return while practicing the hedge against spot price volatility. Moreover, to do this, three models have been elaborated in this work. One is for risk management that depends on the price forecasting, which also depends on the load forecasting. The main advantage of the price forecasting model is the fact that does not make any statistical distribution function for market price assumption.

For solving the model of load and price forecast, PSO technique has been used to find the best regression parameters.

The methodology has been applied to a case study to carry out load and price forecasting. Results demonstrate that this methodology can effectively support handle the decision-support for long-term risk management in power systems.

\section{Acknowledgments}

The authors would like to acknowledge the sponsor and financial support to FCT, FEDER, POCTI, POSI, POCI and POSC for their support to R\&D Projects and GECAD Unit.

\section{Appendix A. List of symbols}

The authors would like to acknowledge the sponsor and financial support to FCT, FEDER, POCTI, POSI, POCI and POSC for their support to R\&D Projects and GECAD Unit.

$C_{i j} \quad$ real monthly load average for month $i$, year $j$

$\hat{C}_{i, j} \quad$ monthly load average forecast for month $i$, year $j$

.

$\operatorname{Var}(\pi) \quad$ variance of the return based on the forecasted price inter-

val for the entire period in analysis (Eur)
$\operatorname{cov}_{i, j}\left(\pi^{\text {max }}, \pi^{\text {min }}\right)$ element $(i, j)$ of the covariance matrix of the
returns for all periods $i$ based on maximum and minimum

val for the entire period in analysis (Eur)
$\operatorname{cov}_{i, j}\left(\pi^{\max }, \pi^{\text {min }}\right)$ element $(i, j)$ of the covariance matrix of the
returns for all periods $i$ based on maximum and minimum

val for the entire period in analysis (Eur)
$\operatorname{cov}_{i, j}\left(\pi^{\max }, \pi^{\min }\right)$ element $(i, j)$ of the covariance matrix of the
returns for all periods $i$ based on maximum and minimum price forecast (Eur) $C\left(P_{g}\right) \quad$ cost to produce $P_{g}($ Eur $/ \mathrm{h})$

parameter associated to the monthly load average of the month $i-1$

parameter associated to the monthly load average of the month $i$, year $j-1$

parameter associated to the monthly load average of the month $i$, year $j-2$

window size to extract statistical information from historical price data

desired confidence level for the monthly price range forecast

maximum monthly market price average for month $i$, year $j$ with confidence level $\alpha$

$i$, year $j$ with confidence level $\alpha$

maximum monthly market price average forecast for month $i$, year $j$ with confidence level $\alpha$

minimum monthly market price average forecast for month $i$, year $j$ with confidence level $\alpha$

monthly market price average of the month $i-1$, year $j$ parameter associated to the load average forecast for the month $i$ to forecast the maximum market price average for the same month

parameter associated to the monthly market price average of month $i-1$ to forecast the maximum market price for month $i$

parameter associated to the load average forecast for the month $i$ to forecast the minimum market price average for the same month

parameter associated to the monthly market price average of month $i-1$ to forecast the minimum market price month $i$

number of historical years used

represents a scale factor to be applied to the monthly load average forecast

revenue of the short position obtained by the producer in the spot market for period $i$, scenario $j$ (Eur)

Market Clearing Price for period $i$, scenario $j$ (Eur/MWh)

energy amount that the producer decides to sell in the spot market for period $i$ (MWh)

forward contracts (Eur)

delivery price of the forward contract (Eur/MWh)

energy amount that the producer decides to sell in forward contracts (MWh)

$j$ (Eur)

premium of the call option (Eur/MWh)

delivery price of the call option (Eur/MWh)

energy associated to the short call position obtained by the producer (MWh)

payoff of the long put position, for period $i$, scenario $j$ (Eur)

premium of the put option (Eur/MWh)

delivery price of the put option (Eur/MWh)

energy associated to the long put position obtained by the producer (MWh)

producer return for the entire period in analysis (Eur)

expected value of the return based on the forecasted price interval for the entire period in analysis (Eur) 

number of the considered periods for the entire period in analysis

producer risk aversion factor

minimum energy that the producer can produce (MWh)

maximum energy that the producer can produce (MWh)

\section{References}

[1] C.P. Rodriguez, G.J. Anders, Energy price forecasting in the Ontario competitive power system market, IEEE Transactions on Power Systems 19 (February(1)) (2004) 366-374

[2] H. Chen, C. Cañizares, A. Singh, ANN-based short-term load forecasting in electricity markets, in: Power Engineering Society Winter Meeting, vol. 2, IEEE, February, 2001, pp. 411-415.

[3] B.R. Szkuta, L.A. Sanabria, T.S. Dillon, Electricity price short-term forecasting using artificial neural networks, IEEE Transactions on Power Systems 14 (August(3)) (1999) 851-857.

[4] F. Azevedo, Z.A. Vale, Short-term price forecast from risk management point of view, in: 13th International Conference on Intelligent Systems Application to Power Systems - ISAP 2005, Arlington - USA, November, 2005, pp. 111-116.

[5] F. Azevedo, Z.A. Vale, Forecasting electricity prices with historical statistical information using neural networks and clustering techniques, in: PSCE - Power Systems Conference and Exposition, Georgia, Atlanta, USA, October, 2006, pp. 44-50.

[6] T. Niimura, Forecasting techniques for deregulated electricity market prices extended survey, in: PSCE - Power Systems Conference and Exposition, Georgia, Atlanta, USA, October, 2006, pp. 51-56.

[7] T. Niimura, H. Ko, K. Ozawa, A day-ahead electricity price prediction based on a fuzzy-neuro autoregressive model in a deregulated electricity market, in: Proceedings of the 2002 International Joint Conference on Neural Networks, vol. 2, May, 2002, pp. 12-17.

[8] L. Hongjie, W. Xiufeng, Z. Weicun, X. Guohua, Market Clearing Price forecasting based on dynamic fuzzy system, in: Proceedings of the 2002 International Conference on Power System Technology, vol. 2, October, 2002, pp. 390396.

[9] J. Contreras, R. Espínola, F.J. Nogales, A.J. Conejo, ARIMA models to predict nextday electricity prices, IEEE Transactions on Power Systems 18 (February(3)) (2003) 1014-1020

[10] F.J. Nogales, J. Contreras, A.J. Conejo, R. Espínola, Forecasting next-day electricity prices by time series models, IEEE Transactions on Power Systems 17 (May(2)) (2002) 342-348.

[11] J. Kennedy, R. Eberhart, Particle swarm optimization, in: IEEE International Conference on Neural Networks, Perth, Australia, 1995, pp. 1942-1948.

[12] Y. Shi, R. Eberhart, Parameter selection in particle swarm optimization, in: Proceedings of the Seventh Annual Conference on Evolutionary Programming, 1998, pp. 591-601.

[13] J. Holland, Genetic Algorithms, Scientific American, July de 1992, pp. 66-72.

[14] M. Mitchell, An Introduction to Genetic Algorithms, MIT Press, 1996.

[15] R. Bjorgan, C. Liu, J. Lawarrée, Financial risk management on a competitive electricity market, IEEE Transactions on Power Systems 14 (November(4)) (1999) 1285-1291.
[16] S. Makkonen, R. Lahdelma, A. Asell, A. Jokinen, Multi-criteria decision support in the liberalized energy market, Journal of Multi-Criteria Decision Analysis 12 (2004) 27-42.

[17] E. Tanlapco, J. Lawarrée, C. Liu, Hedging with futures contracts in a deregulated electricity industry, IEEE Transactions on Power Systems 17 (August(3)) (2002).

[18] R. Bjorgan, H. Song, C. Liu, R. Dahlgren, Pricing flexible electricity contracts, IEEE Transactions on Power Systems 15 (May(2)) (2000) 477-482.

[19] J. Conejo, F.J. Nogales, J.M. Arroyo, Price-taker bidding strategy under price uncertainty, IEEE Transactions on Power Systems 17 (November(4)) (2002) 1081-1088.

[20] J. Conejo, R. Garcia-Bertrand, M. Carrion, A. Caballero, A. Andres, Optimal involvement in futures markets of a power producer, IEEE Transactions on Power Systems $23(\operatorname{May}(2))(2008)$ 703-711.

[21] M. Carrion, J. Conejo, M. Arroyo, Forward contracting and selling price determination for a retailer, IEEE Transactions on Power Systems 22 (November(4)) (2007) 2105-2114

[22] M. Carrion, B. Phipott, J. Conejo, M. Arroyo, A stochastic programming approach to electric energy procurement for large consumers, IEEE Transactions on Power Systems 22 (May(2)) (2007) 744-754

[23] S. Pineda, J. Conejo, M. Carrion, Impact of unit failure on forward contracting, IEEE Transactions on Power Systems 23 (November(4)) (2008) 1768-1775.

[24] F. Black, M. Scholes, The pricing of options and corporate liabilities, Journal of Political Economy 81 (June(81)) (1973) 637-659.

[25] R.C. Merton, Theory of rational option pricing, Bell Journal of Economics and Management Science 4 (4) (1973) 141-183.

Filipe Azevedo received his diploma in 1999, the M.Sc. in 2003, both in Electrical Engineering from Porto University, Portugal, and the Ph.D. degree in 2008 on Electrica Engineering at the University of Trás-os-Montes e Alto Douro (UTAD), Vila Real, Portugal. He is currently an Assistant of Power Systems at the Institute of Engineering - Polytechnic of Porto (ISEP/IPP), Portugal, and a researcher at the Knowledge Engineering and Decision-Support Research Group (GECAD). His main research interests are Economics applied to Energy Markets, Decision-Support System techniques applied to Economics Engineering problems and Artificial Intelligence (A.I.) applications.

Zita A. Vale is a Coordinator Professor of Power Systems at the Institute of Engineering - Polytechnic Institute of Porto (ISEP/IPP), Portugal. She received her diplom in Electrical Engineering in 1986 and her Ph.D. in 1993, both from University of Porto. Her main research interests concern Artificial Intelligence (A.I.) applications to Power System operation and control, Electricity Markets and Distributed Generation. She is involved in several R\&D projects concerning the application of A.I. and Decision-Support techniques to Engineering problems.

P.B. Moura Oliveira is an Assistant Professor of the Engineering Department Systems at the University of Trás-os-Montes e Alto Douro (UTAD), Portugal. He received his diploma in Electrical Engineering in 1991, from the UTAD University, M.Sc. in Industrial Control Systems in1994 and Ph.D. in Control Engineering in 1998, both from Salford University, UK. His main research interests concern Computational Intelligence applications to automation and control.

Hussein M. Khodr received his Ph.D., M.Sc. and Engineer degrees in Electrical Engineering from the José Antonio Echeverría Higher Polytechnic Institute (ISPJAE) in 1997 and 1993, respectively. He is a Former Associate Professor of Electrical Engineering at Universidad Simón Bolívar, Venezuela. He also was a Researcher at INESC Porto, Portugal. Presently, he is a Researcher at GECAD - Knowledge Engineering and Decision-Support Research Group - Polytechnic Institute of Porto (ISEP/IPP). He has participated in a number of projects performed for the local industries. His current research activities are concentrated on planning, operation, and economics of electrical distribution and industrial power systems, power quality, grounding systems and optimization. 